\title{
CLIMATOLOGIA DO COMPORTAMENTO DO PERÍODO CHUVOSO DA REGIÃO SUDESTE DO BRASIL
}

\author{
ROSANDRO BOLIGON MINUZZI ${ }^{1,2}$, GILBERTO CHOHAKU SEDIYAMA ${ }^{1,3}$, \\ ELTON DA MOTTA BARBOSA ${ }^{1,4}$ e JÚLIO CÉSAR FERREIRA DE MELO JÚNIOR ${ }^{5}$ \\ ${ }^{1}$ Universidade Federal de Viçosa, Dep. Engenharia Agrícola, \\ Av. P.H.Rolfs, s/nº, CEP:36570-000 Viçosa - MG, Brasil \\ ${ }^{2}$ E-mail: rbminuzzi@hotmail.com \\ ${ }^{3}$ E-mail: g.sediyama@ufv.br \\ ${ }^{4}$ E-mail: emb blaster@yahoo.com \\ ${ }^{5}$ Universidade Vale do São Francisco - CENAMB \\ Caixa Postal 309, CEP: 48909-810, Juazeiro - BA, Brasil \\ E-mail: juliomelo@univasf.edu.br
}

Recebido Abril 2006 - Aceito Setembro 2006

\begin{abstract}
RESUMO
Foram analisados dados diários de 203 estações pluviométricas localizadas na região Sudeste do Brasil, com o objetivo de caracterizar climaticamente e analisar a tendência do comportamento do período chuvoso. Os resultados indicam que o período chuvoso inicia mais cedo (entre 13 e 22 de setembro) e tem maior duração (210 a 229 dias) na região litorânea de São Paulo. Comportamento oposto ao observado nas regiões Norte e Vale do Jequitinhonha, em Minas Gerais, onde o período chuvoso inicia em média, entre os dias 23 de outubro a 2 de novembro, durando apenas 136 a 155 dias. As datas de início e a duração do período chuvoso estão fortemente correlacionadas entre si, bem como, entre o total de precipitação e a duração do período chuvoso em praticamente todo o Sudeste do Brasil. De modo geral, desde meados da década de 1970, o período chuvoso tem iniciado precocemente e durado mais no Sudeste do Brasil. Quanto à quantidade de chuva, esta tem ocorrido em maiores quantidades somente na área MG3 (sudeste de Minas Gerais) e no estado de São Paulo.
\end{abstract}

Palavras-chaves: Período chuvoso, precipitação e Sudeste do Brasil.

\begin{abstract}
CLIMATOLOGY OF THE RAINY PERIOD BEHAVIOR IN THE SOUTHEAST REGION OF BRAZIL

Daily data from 203 pluviometric stations, located in the Southeast region of Brazil, were studied with the objective to characterize climatically and analyze the tendency of the behavior of the rainy period. The results indicate that the rainy period begins early (between 13 and September $22^{\text {th }}$ ) and has larger duration (210 to 229 days) at the coastal area of São Paulo. Behavior opposed to the observed in the areas North and Vale do Jequitinhonha, in Minas Gerais, where the rainy period begins on average, among October $23^{\text {th }}$ on November $2^{\text {nd }}$, only lasting 136 to 155 days. The duration and the dates at the beginning of the rainy period are strongly correlated, as well as, among the precipitation total and the duration of the rainy period in practically the whole Southeast region of Brazil. In general, from middles of the 1970's, the rainy period has started earlier and lasted more in the Southeast region of Brazil. In regard to the amount of rain, it has been occurred in larger amounts only in the MG3 (Southeast of Minas Gerais) area and in the State of São Paulo.
\end{abstract}

Keywords: Rainy period, precipitation, Southeast of Brazil. 


\section{INTRODUÇÃO}

A distribuição espaço-temporal das chuvas é uma característica regional muito importante, seja para a sociedade como à economia. Além disso, o conhecimento dessa característica pode orientar decisões quanto às medidas necessárias para minimizar os danos decorrentes da irregularidade das chuvas (Piccinini, 1993).

No contexto da agricultura de sequeiro, Stewart (1990) destaca que a estação de crescimento das culturas depende da época em que as chuvas efetivamente começam. Períodos chuvosos com início precoce, em geral, são potencialmente superiores na produtividade das culturas, em relação aos períodos chuvosos de início tardio. Machado et al. (1996) também atentaram na importância do comportamento do período chuvoso para a agricultura. No estudo, os autores definiram as datas de início dos períodos chuvosos (IPC) através de classes e as probabilidades de ocorrência de que as estações chuvosas excedessem durações especificadas. Como resultados, encontraram uma estreita relação entre a data de IPC e a duração do período chuvoso (DPC), ou seja, os inícios precoces do período chuvoso (PC) redundam, na maioria das vezes, em PCs significativamente menores, sendo que, o oposto ocorre quando se têm períodos chuvosos iniciados tardiamente, tendo-se maior duração dos PCs. Em áreas com uma estação seca bem definida e, por vezes severa, como é o caso da região Norte de Minas Gerais, a data de início do período chuvoso (ou estação chuvosa) é um importante parâmetro agroclimático.

A região Sudeste do Brasil possui uma característica climática diversificada, devido a sua topografia, sua posição geográfica e, principalmente, os aspectos dinâmicos da atmosfera, que incluem os sistemas meteorológicos de micro, meso e grande escalas, que atuam direta ou indiretamente no regime pluvial, como a Zona de Convergência do Atlântico Sul (ZCAS) e as Frentes Frias, principais responsáveis pela precipitação pluvial e o Anticiclone Subtropical do Atlântico Sul e o Vórtice Ciclônico de Ar Superior que, dependendo das suas posições, ocasionam grandes períodos de estiagens. Utilizando diferentes limiares de chuva, Alves et al. (2005) mostram que, em média, o início da estação chuvosa na região Sudeste do Brasil acontece na pêntada 57 , ou seja, entre 8 e 12 de outubro, com um desvio padrão de aproximadamente 2 pêntadas. Quanto à diferença entre os extremos das datas de início na área de estudo, os autores explicam que as datas coincidem com a maior freqüência das frentes frias no sul do País, em setembro, e com a fase ativa da ZCAS, durante dezembro.

Quanto à topografia, Minuzzi e Sediyama (2005) realizaram uma análise no comportamento do IPC, da DPC e da precipitação observada no $\mathrm{PC}$, em duas áreas próximas entre si, mas localizadas em altitudes significativamente diferentes, no estado de São Paulo, sendo uma área com estações pluviométricas acima de 1200 metros e, a outra, com estações abaixo de 750 metros de altitude. Encontraram que, mesmo na 'região baixa' o PC mostre estar começando mais cedo e terminado mais tarde, a quantidade de precipitação tem diminuído. Já para a 'região alta', a precipitação não mostrou nenhuma tendência significativa, porém, como observado para a 'região baixa', mas com maior magnitude, o PC também tem iniciado mais cedo e durado mais.

De acordo com Alves et al. (2002) e Paiva (1997), o período chuvoso na região Sudeste do Brasil concentra-se entre os meses de outubro a março, quando ocorrem mais de $80 \%$ do total anual de chuvas. Devido a esta característica, este regime bem definido de precipitação caracteriza-se como um sistema de monção, semelhante ao de uma região monçônica do sudeste da Ásia (Veiga et al., 2002).

Diante das considerações apresentadas, no presente trabalho objetiva-se caracterizar climaticamente e analisar o comportamento do período chuvoso da região Sudeste do Brasil.

\section{DADOS E METODOLOGIA}

Foram utilizados dados pluviométricos de 203 estações localizadas na região Sudeste do Brasil (SEB), sendo 16 estações localizadas no Estado do Rio de Janeiro, 15 no Estado do Espírito Santo, 73 no Estado de Minas Gerais, estando incorporadas a Rede Hidrometeorológica, da Agência Nacional de Águas (ANA) e 99 estações no Estado de São Paulo, pertencentes ao Departamento de Águas e Energia Elétrica (DAEE) (Figura 1). Essa seleção levou em consideração as estações que possuíam número suficiente de dados no período chuvoso de 1950/51 a 1999/2000, além de suas séries serem caracterizadas como homogêneas, após a realização do teste denominado 'run test' ou teste de seqüência. A referida metodologia consiste na contagem do número de ocorrências de valores observados, no caso, totais anuais de precipitação de anos sem falhas, situados acima e abaixo da mediana, testando o resultado da contagem mediante o uso de uma tabela de distribuição.

As datas de início e final do período chuvoso (IPC e FPC, respectivamente), foram determinadas conforme critério proposto por Sansigolo (1989). O seu início consta, como sendo a primeira data, após $1^{\circ}$ de setembro, que seja observada uma quantidade mínima de $20 \mathrm{~mm}$ de chuva totalizada em um ou dois dias seguidos, apresentando nos próximos 30 dias, pelo menos um dia de chuva em cada período de 10 dias. O FPC será o primeiro dia de um período seco com pelo menos 15 dias de duração que termine depois do dia 15 de março.

Foi considerado como "não satisfeito" o IPC que não atendeu as exigências até o dia $1^{\circ}$ de março e como dia chuvoso, a aquele em que ocorreu uma precipitação de pelo menos 


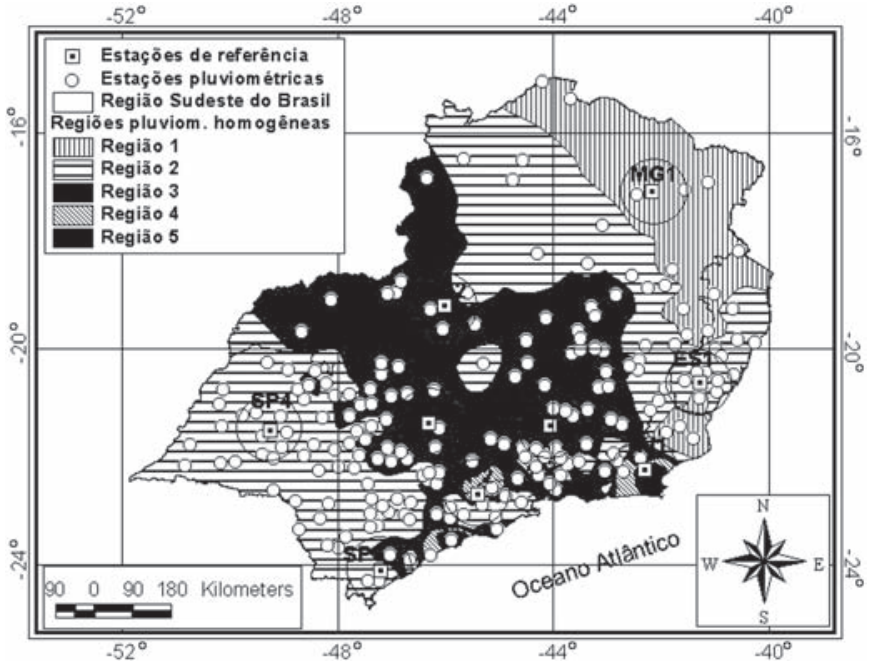

Figura 1 - Localização geográfica das estações pluviométricas analisadas e das áreas selecionadas com suas respectivas simbologias utilizadas no estudo.

$1,0 \mathrm{~mm}$, pois uma lâmina de precipitação menor do que essa geralmente não infiltra no solo.

As correlações existentes entre o IPC, DPC e a precipitação registrada durante o período chuvoso, foram obtidas por intermédio do Método da Regressão Linear para áreas predefinidas do SEB. Para essas áreas, primeiramente, optou-se na escolha de pelo menos uma estação como referência, com série de dados a mais completa possível e, a partir deste selecionado, considerou-se as estações pluviométricas envolvidas num raio de $80 \mathrm{~km}$, desde que, estejam na mesma região pluviométricamente homogênea da estação de referência. A escolha da referida distância deve-se primeiramente, por ser adotada na técnica de preenchimento de dados meteorológicos faltosos entre estações localizadas em uma mesma região climaticamente homogênea, e segundo, por ter satisfeito um número considerável de estações pluviométricas para o estudo (Figura 1).

A partição da variação da duração ou os intervalos dentro das quais à variação da precipitação ocorre, foi realizada mediante análise autoespectral. Visando suavizar os estimadores do espectro, para tentar encontrar um estimador consistente ao espectro real, foram aplicados pesos à função da convariância estimada. Dentre as muitas funções pesos (termo de filtragem), adotadas na literatura, utilizou-se a denominada 'Janela de Parzen'. O número de 'lags' utilizados na suavização da função covariância, considerou o valor de aproximadamente $25 \%$ do número total de dados da série. Para evitar que possíveis picos, sejam simplesmente devido a flutuações aleatórias, as periodicidades foram testadas ao nível de significância de 5\%, utilizando o teste de Fisher. A adoção da análise autoespectral, foi restrita a duas áreas localizadas em extremos opostos norte-sul do SEB. O critério adotado para tal escolha, considera que os sistemas sinóticos atuantes no
SEB não influenciam de forma semelhante e simultâneamente, áreas localizadas nestes extremos. Por exemplo, a atuação da Alta Subtropical do Atlântico Sul sobre o extremo norte do SEB, da mesma forma que inibe a formação de nuvens, impede que frentes frias avancem ou a ZCAS atue na referida região. Conseqüentemente, estes sistemas acabariam influenciando o extremo sul do SEB, favorecendo a maior ocorrência de chuvas.

O cálculo do IPC e FPC foram determinados por meio de um programa desenvolvido em linguagem Object Pascal para Delphi.

O software ArcView GIS 3.2a foi utilizado para a geoespacialização dos resultados referentes ao IPC e a DPC. Utilizouse o interpolador linear IDW (Inverse Distance Weighted) do software, em que, o peso da célula a ser interpolada é dado por uma média ponderada que utiliza o peso dos pontos de controle mais próximos (12 pontos), ponderados pelo inverso da distância elevado a um expoente $m$ (quarta potência).

\section{RESULTADOS E DISCUSSÕES}

A Figura 2 apresenta os intervalos referentes às datas na qual, o período chuvoso (PC) tem início na região Sudeste do Brasil (SEB). O início do período chuvoso (IPC) tende a ser mais precoce em grande parte do litoral paulista, onde o $\mathrm{PC}$ tem início em média em meados de setembro, enquanto nas regiões Norte e Vale do Jequitinhonha, em Minas Gerais, a época das chuvas inicia em média no final de outubro. As "ilhas" existentes dentro dos intervalos de 3 a 12 de outubro e de 13 a 22 de outubro, são resultantes de apenas uma estação pluviométrica.

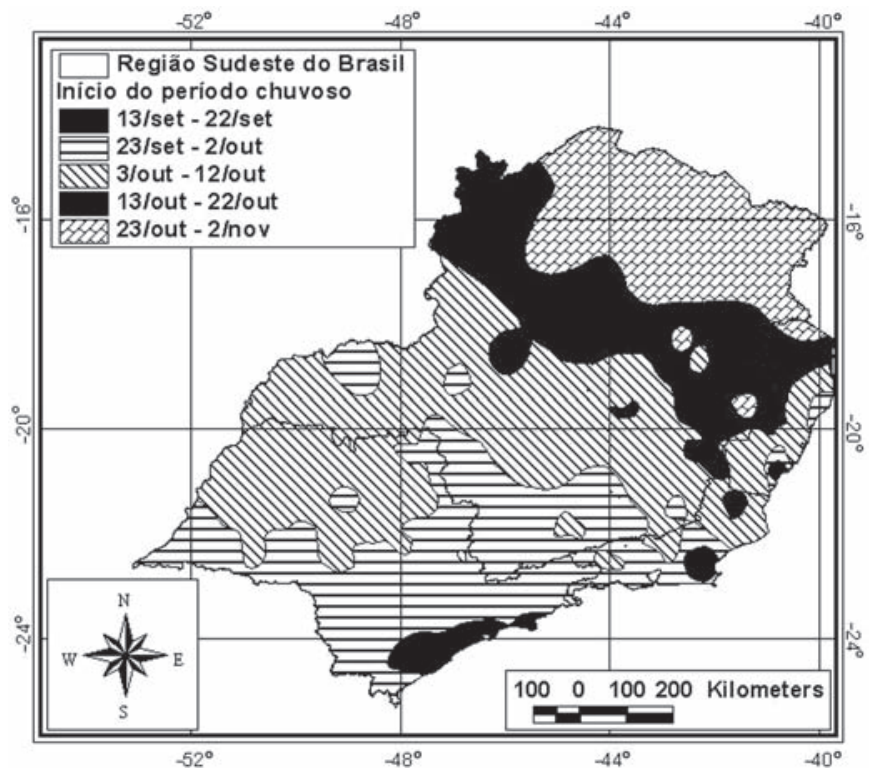

Figura 2 - Intervalos das datas de início do período chuvoso na região Sudeste do Brasil. 
Quanto à duração do período chuvoso (DPC), este tende ao decréscimo do litoral sul paulista a região de Santos-SP, durando em média de 210 dias a 229 dias, até às regiões Norte e Vale do Jequitinhonha, onde o PC, dura apenas de 136 dias a 155 dias. Em suma, observa-se que na maior parte do SEB, o PC, dura entre 155 dias e 173 dias.

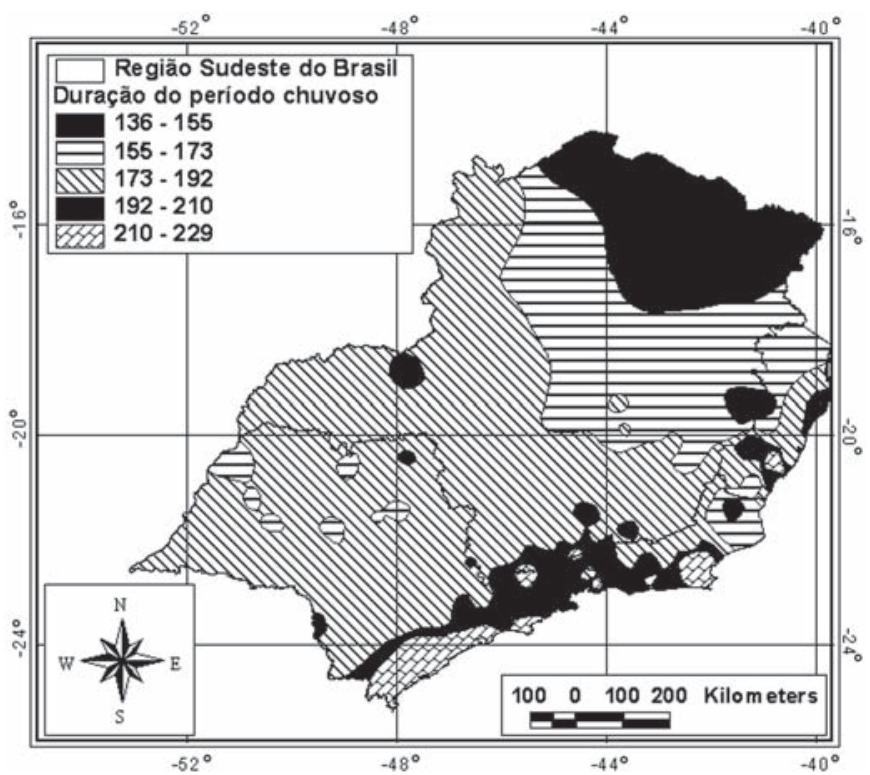

Figura 3 - Intervalos em dias, da duração do período chuvoso na região Sudeste do Brasil.

A configuração espacial dos resultados, referentes ao IPC e DPC evidenciam a atuação dos sistemas sinóticos e dos aspectos geográficos continentalidade, proximidade do oceano e o relevo, como principais fatores. Toma-se como principais exemplos, a orientação noroeste-sudeste, das ZCAS e as trajetórias comumente observadas das frentes frias, que durante o inverno quando começam a adentrar no SEB, geralmente são deslocadas para o Atlântico ou passam sobre este, influenciando somente as regiões litorâneas. Este comportamento persiste até os períodos iniciais da época das chuvas, sempre considerando os efeitos da orografia local, como a Serra da Mantiqueira.

A Tabela 1 evidencia a forte correlação existente entre a data do IPC e a DPC, para todas as áreas analisadas. Entre a precipitação (P) e a DPC, os fatores de correlação foram menores, porém, salvo a área MG1, nas demais, as correlações foram significativas a $95 \%$. Uma explicação plausível para as baixas correlações da precipitação com o IPC e DPC, em MG1, pode ser, devido ao maior número de dias secos. Nas regiões mais secas do SEB, os intervalos sem chuva, entre os dias chuvosos são maiores em relação às demais regiões, principalmente às localizadas em maiores latitudes. Assim, estes intervalos são, ora suficientes, ora não, para atender aos critérios que definem as datas de IPC e FPC, mesmo que, em menores quantidades, as chuvas já tenham iniciado ou permaneçam ocorrendo, respectivamente.

Dentre as regressões realizadas, a relação entre a precipitação e o IPC foi a que apresentou o menor número de fatores de correlação significativos, sendo observado apenas nas áreas MG2, SP1, SP2 e SP3. Estes resultados mostram a possibilidade de utilizar a data de IPC como parâmetro previsor da duração do período chuvoso e da precipitação observada no PC, principalmente no Estado de São Paulo.

Tabela 1 - Coeficientes de correlação entre o IPC, a DPC e a precipitação (P) ocorrida durante o período chuvoso. Valores em destaque, são linearmente significativos a $95 \%$

\begin{tabular}{cccc}
\hline & DPCxIPC & PxDPC & PxIPC \\
\hline ES1 & $\mathbf{- 0 , 5 7}$ & $\mathbf{0 , 4 1}$ & $-0,16$ \\
MG1 & $\mathbf{- 0 , 7 1}$ & 0,20 & $-0,17$ \\
MG2 & $\mathbf{- 0 , 7 3}$ & $\mathbf{0 , 4 0}$ & $\mathbf{- 0 , 3 2}$ \\
MG3 & $\mathbf{- 0 , 7 6}$ & $\mathbf{0 , 4 0}$ & $-0,22$ \\
SP1 & $\mathbf{- 0 , 7 6}$ & $\mathbf{0 , 3 4}$ & $\mathbf{- 0 , 3 1}$ \\
SP2 & $\mathbf{- 0 , 7 5}$ & $\mathbf{0 , 5 8}$ & $\mathbf{- 0 , 4 2}$ \\
SP3 & $\mathbf{- 0 , 5 8}$ & $\mathbf{0 , 6 5}$ & $\mathbf{- 0 , 3 7}$ \\
\hline
\end{tabular}

O comportamento do IPC nos primeiros 25 anos em relação aos últimos 25 anos, no período e para as áreas em estudo, consta na Figura 4. A tendência foi igual para todas as áreas, ou seja, o PC nos últimos 25 anos, passou a iniciar precocemente. Porém, uma análise mais minuciosa mostra que os valores médios encontrados no período de 1975/76 a 1999/2000, estão dentro do intervalo de confiança de $95 \%$ determinado para o período de 1950/51 a 1974/75, em todas as áreas, exceto em SP2.

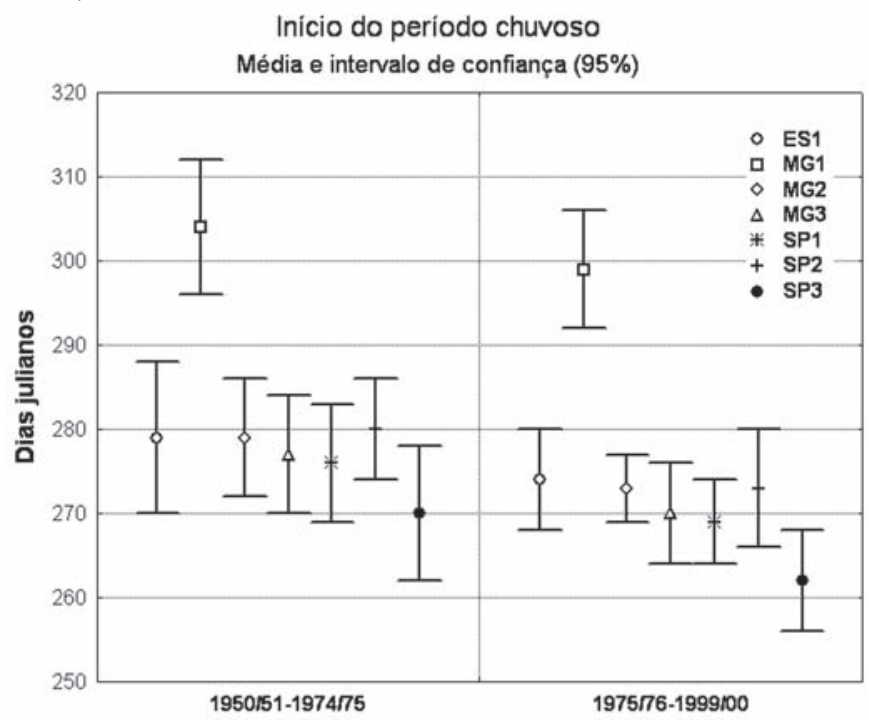

Figura 4 - Médias e intervalos de confiança de 95\%, para o início do período chuvoso nos períodos de 1950/51 a 1974/75 e de 1975/76 a $1999 / 2000$. 
Tendo conhecimento da expressiva relação existente entre o IPC e a DPC (Tabela 1), pressupõe-se que o comportamento da DPC de 1950/51 a 1974/75 e de 1975/76 a 1999/2000, seja o oposto ao encontrado para o IPC (Figura 4). A Figura 5 vem a confirmar essa afirmação, ou seja, assim como foi indicada uma tendência do PC iniciar precocemente, o período chuvoso passou a durar mais em todas as áreas analisadas. Outras considerações são realizadas nesta análise, como a significativa diminuição do intervalo de confiança nos últimos 25 anos, nas áreas ES1 e MG1, sugerindo menor variação nas datas de IPC e a diferença entre os dois períodos de 25 anos, nos valores dos intervalos de confiança das áreas SP2 e SP3, enfatizando uma maior variação observada da DPC.

A precipitação durante o período chuvoso entre os dois períodos de 25 anos, mostra valores expressivos somente nas áreas MG3, SP1, SP2 e SP3, sendo mais notável nas duas últimas (Figura 6). No entanto, os resultados de todas as áreas são unânimes em apontar uma tendência de aumento da precipitação, sendo proporcional ao aumento da DPC (Tabela $1 \mathrm{e}$ Figura 5).

Para a análise do comportamento climático da precipitação por período chuvoso, foram selecionadas as áreas MG1 e SP3, devido as suas localizações e pela correlação a $95 \%$ de significância $(\mathrm{r}=-0,47)$ entre o regime pluviométrico de ambas.

Na Figura 7 consta à análise de densidade espectral da precipitação, para as áreas MG1 (Figura 7a) e SP3 (Figura 7b). Os resultados em MG1 e SP3 indicam, respectivamente, uma periodicidade a longo prazo de aproximadamente 11 e 12 anos, porém, somente nesta, a periodicidade é significativa a $5 \%$. No entanto, estas periodicidades são coerentes a outros

Duração do periodo chuvoso

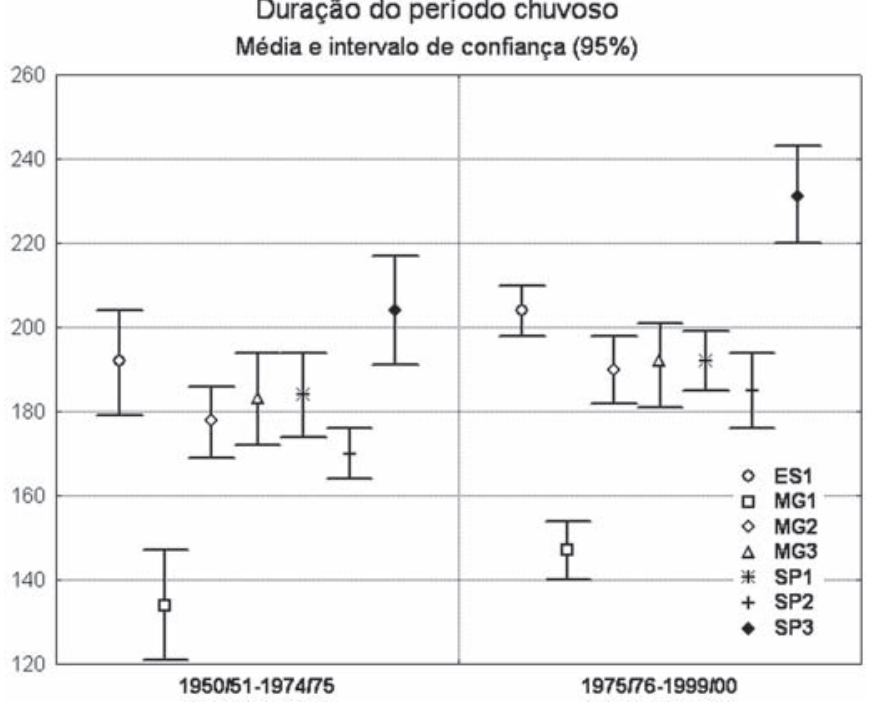

Figura 5 - Médias e intervalos de confiança de 95\%, para a duração do período chuvoso nos períodos de 1950/51 a 1974/75 e de 1975/76 a 1999/2000. estudos, inclusive quando apontam a associação com outros fenômenos, como o Ciclo Solar de 11 anos. Deve-se atentar ao fato de associar pequenas periodicidades como as observadas na Figura 7 (três a quatro anos, aproximadamente), com a ocorrência de fenômenos climáticos como o El Niño. Primeiro, porque de uma maneira geral, este comportamento é natural da precipitação e, segundo, há controvérsias em estudos que visam definir uma periodicidade do citado fenômeno climático. Soma-se a isto, a hipótese apresentada por Trenberth e Hoar (1997) de que o aumento incomum na freqüência e amplitude dos eventos El Niño Oscilação Sul (ENOS), nas décadas de 80 e 90, significativamente diferente dos comportamentos em séculos passados, possa estar associado a fatores antropogênicos, resultantes do evidente aumento nas concentrações dos gases de efeito estufa nas últimas décadas. Porém, até certo ponto, estes resultados entram em conflito aos encontrados por Latif et al. (1997), que objetivaram analisar dentre três teorias, qual a responsável pelas anomalias de precipitação ocorridas na década de 1990. Os autores chegaram a interessante conclusão de que o ENOS é certamente a mais forte flutuação na escala de tempo interanual, mas a variabilidade decadal não pode ser descrita exclusivamente como uma modulação decadal do ENOS, sugerindo que o modo decadal independe do ENOS e é uma fonte para a irregularidade do fenômeno climático. Além do que, foi o responsável pelas anomalias observadas em grande parte dos anos 90.

Apresenta-se, na Figura 8 ( 8 a e 8b), a variação temporal da precipitação observada durante os períodos chuvosos de 1950/51 a 1999/2000, nas áreas MG1 (Figura 8a) e SP3 (Figura 8b), com suas respectivas, médias climáticas e médias

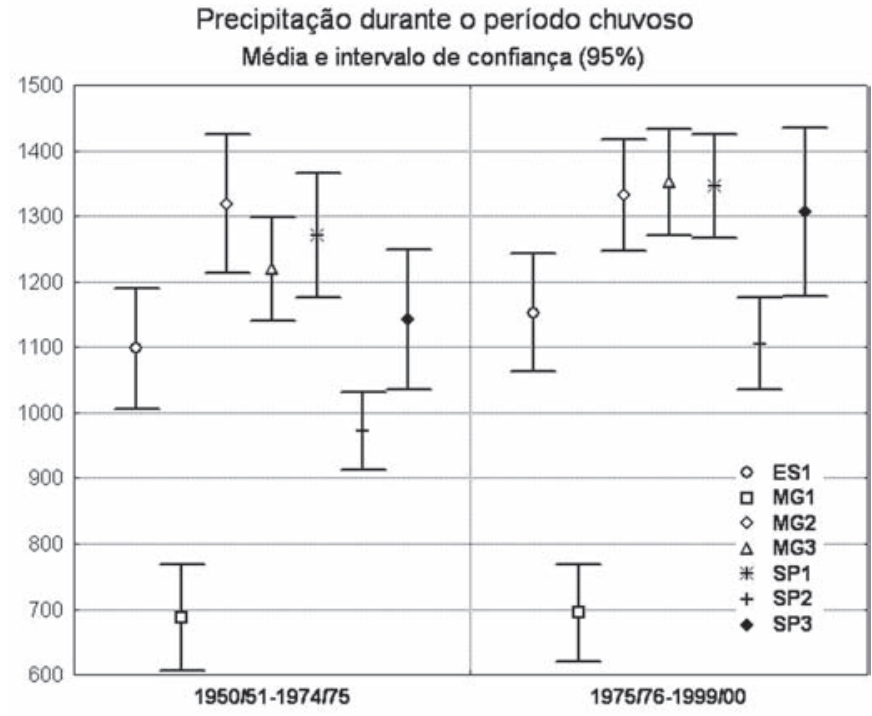

Figura 6 - Médias e intervalos de confiança de $95 \%$, para a precipitação observada durante o período chuvoso nos períodos de 1950/51 a 1974/75 e de 1975/76 a 1999/2000. 
móveis de 11 e 12 anos, atendendo aos resultados encontrados na Figura 7. Isto, por visar neste estudo, possíveis oscilações climáticas de longo prazo na escala temporal. Em MG1, ao contrário pelo sugerido na área SP3, não se nota uma tendência expressiva da precipitação. Enquanto, nesta (SP3), observa-se uma tendência de aumento da precipitação, sendo destacável o período de estiagem nos anos de 1950, havendo em 1950/51, a menor quantidade pluviométrica registrada no período em análise.

Fazendo juz a tendência estabelecida, na década de 1990, observou-se sete PCs com anomalias positivas de precipitação, ocorrendo as maiores quantidades de todo o período, nos anos de $1995 / 96$ e de $1997 / 98$.

a)

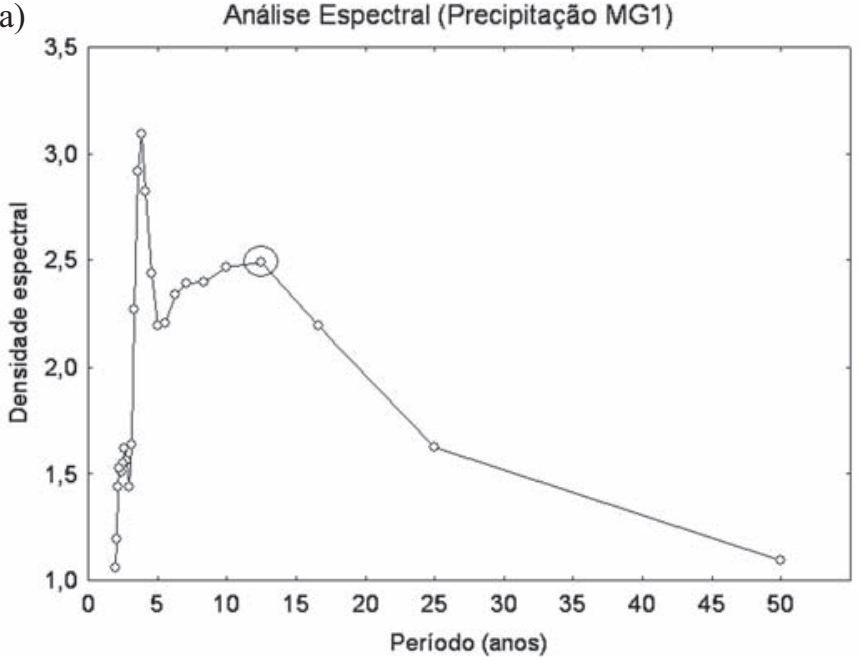

b)

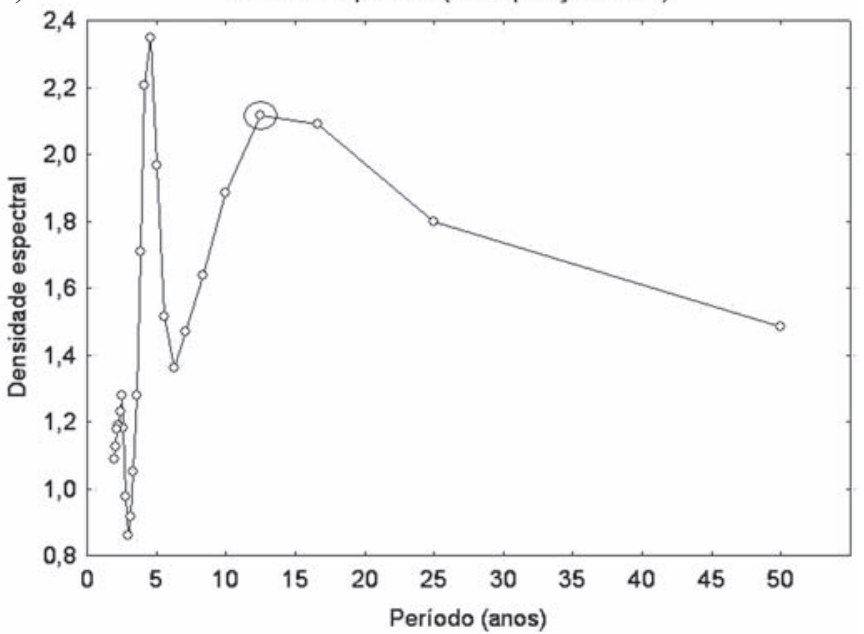

Figura 7 - Densidade espectral referente à quantidade total de precipitação, para os períodos chuvosos de 1950/51 a 1999/2000, nas áreas MG1 (7a) e SP3 (7b).
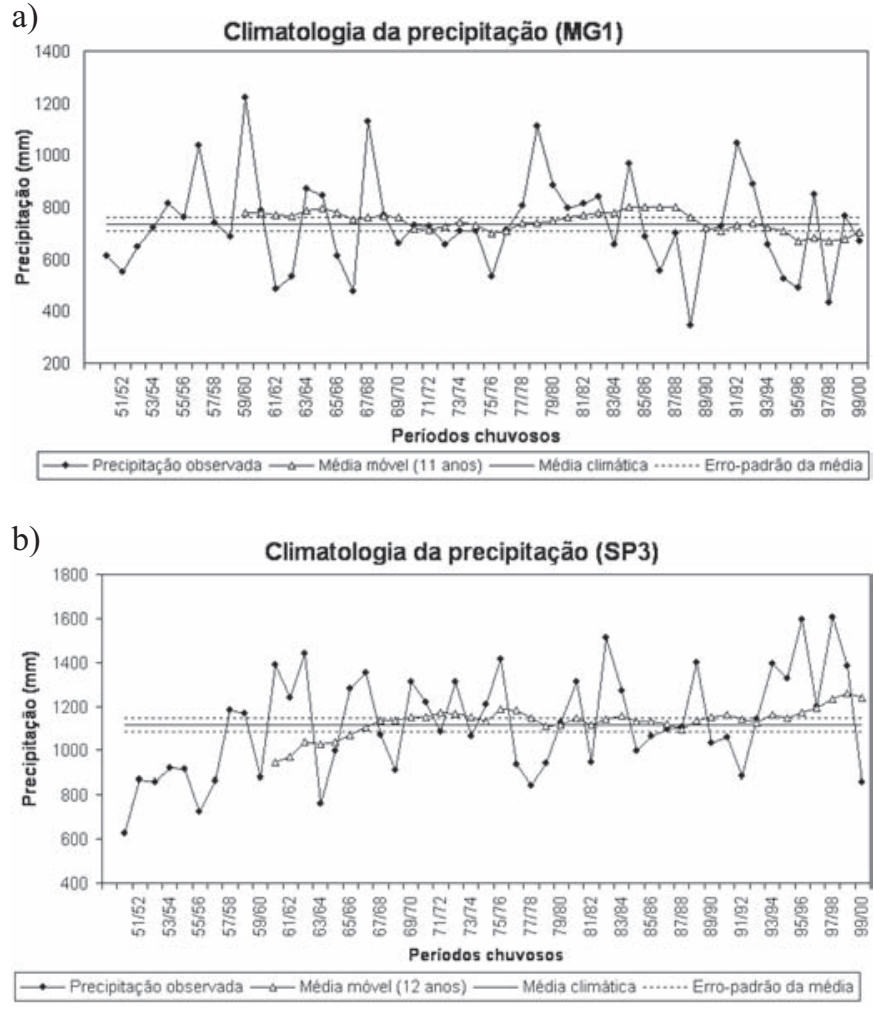

Figura 8 - Variabilidade temporal da precipitação, para os períodos chuvosos de 1950/51 a 1999/2000, com tendência na média móvel, para as áreas MG1 (8a) e SP3 (8b).

\section{CONCLUSÕES}

Diante dos resultados encontrados, pode-se concluir que:

- O período chuvoso (PC) tem início precoce em grande parte do litoral paulista, ocorrendo em meados de setembro, enquanto, nas regiões Norte e Vale do Jequitinhonha, em Minas Gerais, a época das chuvas inicia em média, no final de outubro. De forma análoga, a duração do período chuvoso (DPC) acompanha esse comportamento, ou seja, tende a ser maior do litoral sul paulista até a região de Santos-SP, durando em média de 210 dias a 229 dias, enquanto nas regiões Norte e Vale do Jequitinhonha, o PC, dura apenas de 136 dias a 155 dias.

- As Regressões Lineares evidenciam as fortes relações existentes entre o início do período chuvoso, a DPC e a precipitação durante o período chuvoso, principalmente no estado de São Paulo. A exceção ficou restrita a área MG1, onde não houve correlação da precipitação com o IPC e a DPC, possivelmente devido aos maiores intervalos secos, entre os dias chuvosos, sendo estes intervalos, ora suficientes, ora não, para atender aos critérios que definem as datas de IPC e FPC, mesmo que, em menores quantidades, 
as chuvas já tenham iniciado ou permaneçam ocorrendo, respectivamente.

- Desde meados da década de 1970, o período chuvoso tem iniciado precocemente e durado mais, no Sudeste do Brasil. Quanto à precipitação, esta tem ocorrido em maiores quantidades somente na área MG3 e no estado de São Paulo.

- A variabilidade temporal entre as áreas MG1 e SP3, mostram comportamentos opostos da precipitação durante os mesmos períodos, ou seja, enquanto a média móvel de uma área indica valores acima da média, na outra, observa-se comportamento oposto.

\section{AGRADECIMENTOS}

Os autores agradecem a ANA, ao DAEE pela disponibilidade dos dados de precipitação e ao CNPq pelas bolsas de estudos e financiamento parcial do projeto.

\section{REFERÊNCIAS BIBLIOGRÁFICAS}

ALVES, L.M.; MARENGO, J.A.; CAMARGO JR., H.; CASTRO, C. Início da estação chuvosa na região Sudeste do Brasil: Parte 1 - Estudos observacionais. Revista Brasileira de Meteorologia, v.20, n.3, p.385-394, 2005.

ALVES, L.M.; MARENGO, J.A.; CASTRO, C.A.C. Início das chuvas na região Sudeste do Brasil: análise climatológica. In: CONGRESSO BRASILEIRO DE METEOROLOGIA, 12, 2002, Foz do Iguaçu. Anais... Foz do Iguaçu: SBMET, 2002. 1 CD-ROM.

LATIF, M.; KLEEMAN, R.; ECKERT, C. Greenhouse warming, decadal variability, or El Niño? An attempt to undestand the anomalous 1990s. Journal of Climate, v.10, n.9, p.22212239, 1997.

MACHADO, M.A.de M.; SEDIYAMA, G.C.; COSTA, J.M.N.da; COSTA, M.H. Duração da estação chuvosa em função das datas de início do período chuvoso para o estado de Minas Gerais. Revista Brasileira de Agrometeorologia, v.4, n.2, p.73-79, 1996.
MINUZZI, R.B.; SEDIYAMA, G.C. Variabilidade do período chuvoso em regiões de alta e baixa altitudes. In: CONFERÊNCIA REGIONAL SOBRE MUDANÇAS GLOBAIS: AMÉRICA DO SUL, 2, 2005, São Paulo. Anais... São Paulo: IEA, 2005. 1 CD-ROM.

PAIVA, C.M. Determinação das datas de início e fim da estação chuvosa e da ocorrência de veranicos na Bacia do Rio Doce. 1997. 65f. Dissertação (Mestrado em Meteorologia Agrícola) - Faculdade de Engenharia Agrícola, Universidade Federal de Viçosa, Viçosa, 1997.

PICCININI, M.R.D. Distribuições de probabilidade de precipitação de intensidade máxima para Piracicaba, SP. 1993. 81f. Dissertação (Mestrado em Estatística e Experimentação Agronômica) - Escola Superior de Agricultura “Luiz de Queiroz", Universidade de São Paulo, Piracicaba, 1993.

SANSIGOLO, A. S. Variabilidade Interanual da estação chuvosa em São Paulo. Climanálise, v. 4, n.9, p.40-43, 1989.

STEWART, J. I. Effective rainfall analysis to guide farm and predict yields. In: ANNUAL GENERAL MEETING OF THE SOIL SCIENCE SOCIET OF EAST AFRICA, 1980, Arusha. Proceedings... Arusha, 1990, p.247.

TRENBERTH, K.E.; HOAR, T.J. El Niño and climate change. Geophysical Research Letters, v.24, n.23, p.3057-3060, 1997.

VEIGA, J.A.P.; ORSINI, J.A.M.; RAO, V.B. A influência das anomalias de TSM dos oceanos Atlântico e Pacífico sobre as chuvas de monção da América do Sul. Revista Brasileira de Meteorologia, v.17, n.2, p.181-194, 2002. 